\title{
S Velocity Probing of Ontong-Java Plateau by Analyzing Seismograms of B041196C Earthquake
}

\author{
Bagus Jaya Santosa ${ }^{1}$
}

\begin{abstract}
This research investigates the $S$ wave velocity structure under Ontong-Java Plateau in Equator Western Pacific using seismogram analysis of B041196F earthquake at various observatory stations. The analyzed wave phases are the $S$ wave, Love and Rayleigh surface wave phases and core reflected $\mathrm{ScS}$ and $\mathrm{ScS}_{2}$ wave phases. Seismogram comparison shows different discrepancies that depend on the azimuth direction from hypocenter. South East area of OJP has positive anomaly that differs from the other previously seismological research in the same area. Eastwards area of OJP has negative anomaly like the other result of seismological research. On other azimuth direction indicates that positive anomaly occurred not only in the upper mantle but also at mantle layers till CMB.
\end{abstract}

Keywords - Seismogram comparison; $\mathbf{S}$ wave velocity anomaly; vertical anisotropy in the mantle layers till CMB.

\section{INTRODUCTION}

$\mathrm{T}$ he topic is potentially of interest because the seismic structure of flood basalt provinces are poorly known and they may constrain models of flood basalt formation. The Ontong-Java Plateau (OJP) is of particular interest because it is one of the few oceanic flood basalt provinces as well.

This paper presents results of the seismogram analysis on the $\mathrm{S}$ wave, the Love and Rayleigh surface waves considering the characteristics of the mantle layers beneath the Ontong-Java Plateau. OJP has the form of the letter L, and is the largest igneous rock province (LIP) that is located in South West Pacific between the south border to Solomon Islands and the north border to Carolina Islands.

In a previously seismological experiment, Gomer and Okal [1] used the seismogram analysis of broadband data from a deep earthquake $(511 \mathrm{~km})$ at two observatory stations, respectively in PATS and CTAO to interpret the characteristics of the $S$ wave velocity in mantle layers beneath OJP through the analysis of the travel time difference of the $\mathrm{ScS}_{2}-\mathrm{ScS}_{1}$.

The travel time difference was measured through cross correlation process between the waveform of $\mathrm{ScS}_{2}$ and $\mathrm{ScS}_{1}$ in the broadband seismogram data. To this area they got the travel time difference of 3 seconds between the wave $\mathrm{ScS}_{2}$ and $\mathrm{ScS}_{1}$; this indicated that the structure of the earth mantle layers beneath OJP had the negative $\mathrm{S}$ wave velocity anomaly compared to $\mathrm{S}$ wave

${ }^{1}$ Bagus Jaya Santosa is with the Department of Physics, Faculty of Mathematics and Natural Science, Institut Teknologi Sepuluh Nopember, Surabaya, 60111, Indonesia. E-mail: bjs@physics.its.ac.id velocity structure of the standard isotropic earth model PREM [2].

In previously passive seismic experiment, Richardson et al. [3] used four spread stations around Caroline's Island and Nauru to interpret the earth's crust structure under OJP using the Partial Waveform Inversion method (PWI) to the Rayleigh wave. They found that in general the thickness of the earth's crust is $33 \mathrm{~km}$ and a thickness of the maximum $38 \mathrm{~km}$ in the direction to the south from the plateau of OJP. Similar crustal thickness is reported for the structure of the other ocean earth's crust which is believed had the form close to mid-ocean fire mountains, included Plateau Tuamotu $(25 \mathrm{~km})$

The two previous articles produced the earth model with the negative $\mathrm{S}$ wave velocity structure to the depth $300 \mathrm{~km}$ under OJP, with the lateral dimension $600 \mathrm{~km}$, and featuring the $\mathrm{S}$ wave speed deficiency of $5 \backslash \%$. The crust velocity reaches below $4 \mathrm{~km} / \mathrm{s}$ compared with PREM [2]. Such low speed structure in the depth like previously is reported only in areas that contained the center of the expanding active earth's crust, like in Iceland [4], and is related to the hot anomaly.

\section{Methodology}

The method is used in this research is different from the method used by seismological researchers previously. They used residual travel time in the study heterogeneity in the upper mantle layers $[5,6]$. The travel time difference is measured by carrying out the cross correlation between two wave phases, $\mathrm{ScS}_{\mathrm{n}}$ and $\mathrm{ScS}_{\mathrm{j}}$, where as the standard is taken from the travel time difference of the similar synthetic wave which is constructed from the isotropic PREM earth model. To calculate the synthetic seismogram, the reflectivity method is used, where the approach of earth-flattening transformation (EFT) is required.

In this research, the measured seismogram is compared with the synthetic one that is constructed from the anisotropic PREMAN earth model, in the time domain and in the three Cartesian components simultaneously. The synthetic seismogram is calculated with the Gemini method $[7,8]$, where the EFT approach is not required. The travel time difference and the waveform is measured by the seismogram comparison directly by measuring the delay or the advance of the location of the maximum or minimal of the waveform, as well as the waveform [9].

Table 1 presents the used observatory stations, which the recorded seismograms will be analyzed. The seismogram is generated by B041196C earthquake, where the location of the earthquake hypocenter is $3.4^{0}$ 
North Latitude, $10.91{ }^{0}$ West Longitude, and depth of 38 $\mathrm{km}$.

The Fig. 1 presents the vertical projection of the wave paths from earthquake hypocenter to observatory stations that are used in this research. It could be seen in the Fig. 1 that the wave paths from the B041196C earthquake hypocenter to the HNR station and MSVF cross fully the OJP, where these two stations are located in Solomon and Fiji Islands respectively.

TABLE 1

OBSERVATORY STATIONS USED IN THIS RESEARCH

\begin{tabular}{llll}
\hline No & Latitude $^{\circ}$ & \multicolumn{1}{c}{ Longitude $^{\circ}$} & \multicolumn{1}{c}{ Station } \\
\hline 1 & -18.08 & 178.25 & MSVF, Fiji \\
2 & -9.43 & 159.95 & HNR, Solomon Islands \\
3 & -20.09 & 146.25 & CTAO, Queensland \\
4 & -19.93 & 134.25 & WRAB, Northern Territory \\
5 & -32.93 & 117.23 & NWAO, Western Australia \\
6 & 42.91 & 147.32 & TAU, South Australia \\
7 & 13.59 & 144.87 & GUMO, Marianas Islands \\
8 & -9.41 & 147.16 & PMG, New Guinea \\
\hline
\end{tabular}

\section{SEISMOGRAM ANALYSIS AND FITTING, AND DISCUSSION}

First we will see how the seismogram compare, if the analysis is carried out at the MSVF station in the Fiji Islands, with the epicentral distance of $17.60^{\circ}$, such a close epicentral distance. The Fig. 2a shows that the $\mathrm{S}$ wave disappears in the Love surface wave, which has strong amplitude because amplitude reduction of the surface wave is proportional inverse to the square root of epicentral distance, whereas the amplitude decrease of the body wave is proportional inversely to the epicentral distance. The discrepancy is observed to the synthetic Love surface wave from the PREMAN that arrives later than the measured one. Notice the delay of the Rayleigh wave, which is not as great as the Love wave.

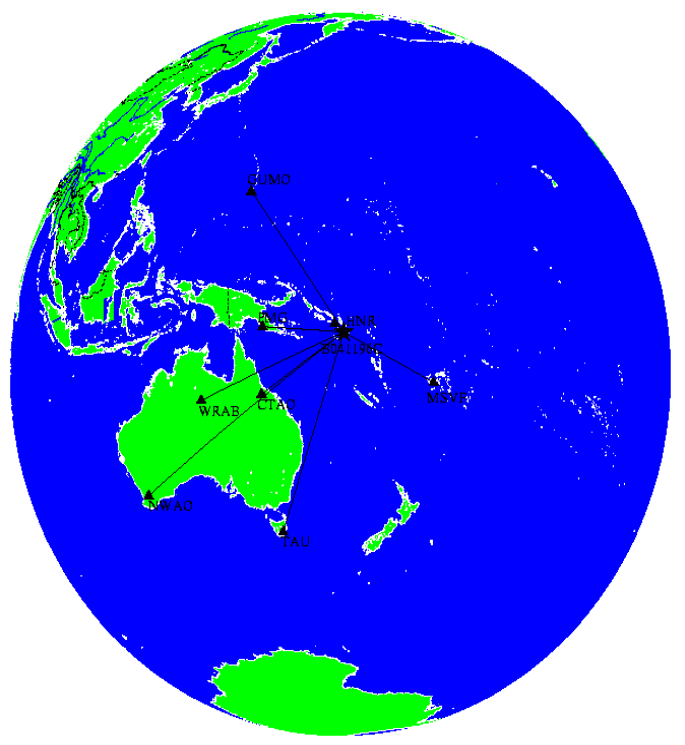

Fig. 1. The vertical projection of wave paths from B041196C earthquakes epicenter to the observatory stations

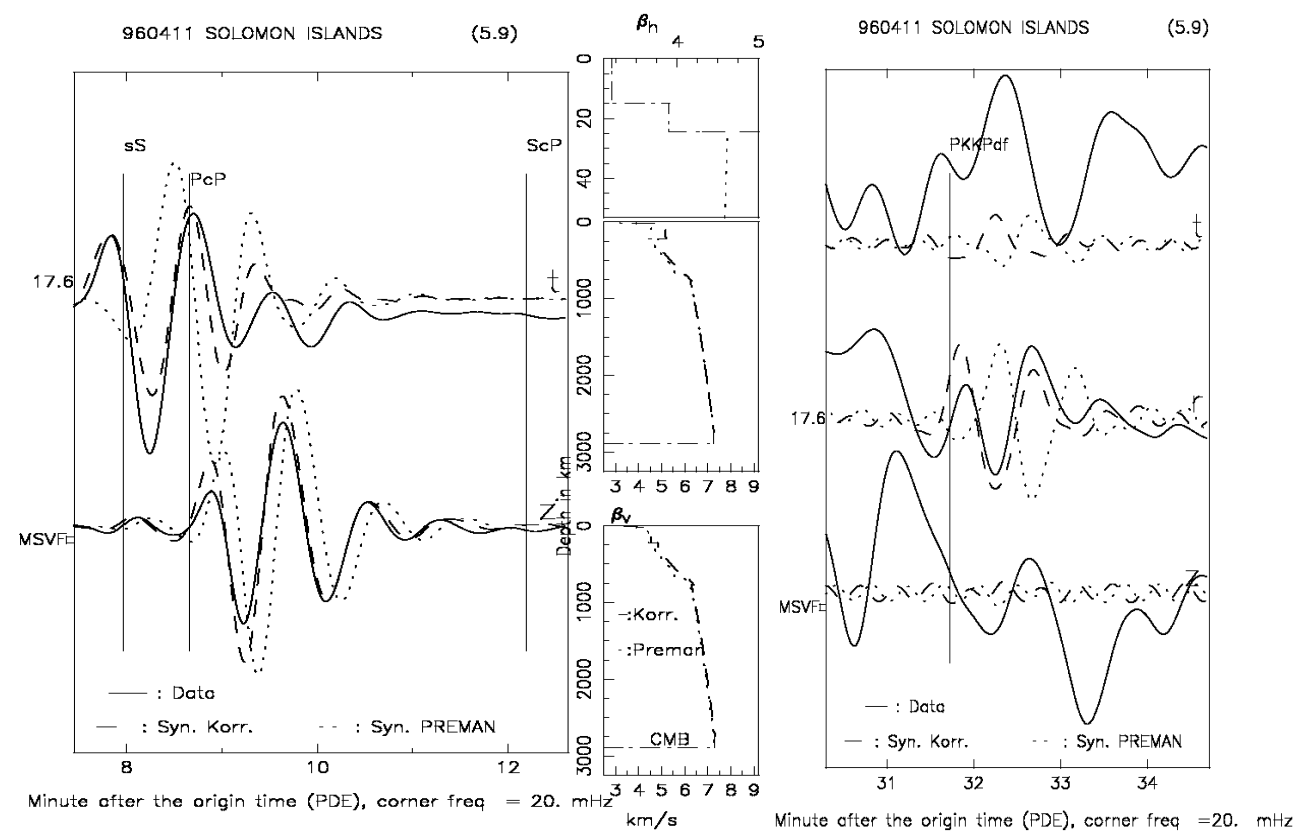

Fig. 2. The seismogram fitting and analysis of the B041196C earthquake in MSVF station: a) S, Love \& Rayleigh waves; b) $\mathrm{ScS}_{2}$ wave 

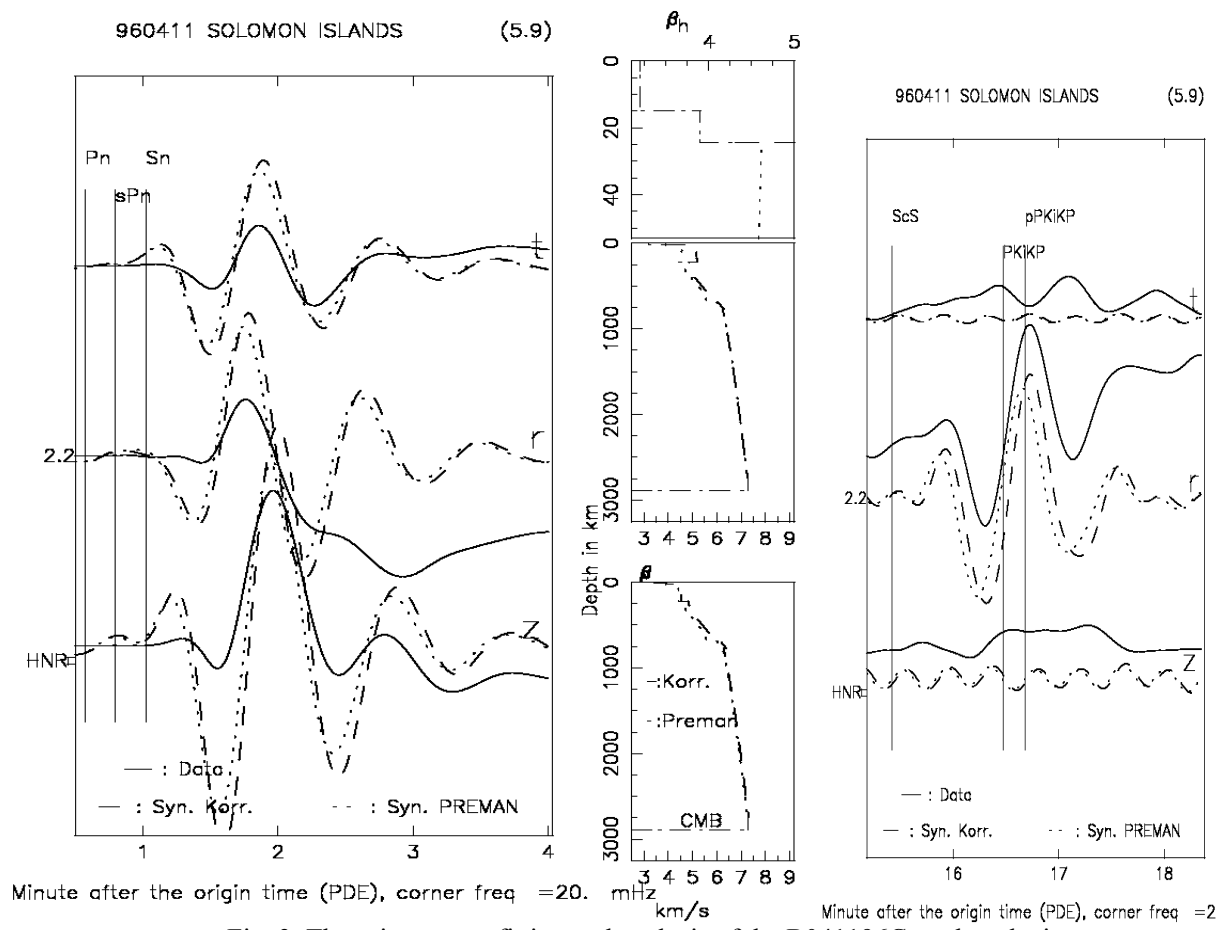

Minute after the origin time (PDE), corner freq $=20$.

Fig. 3. The seismogram fitting and analysis of the B041196C earthquake in HNR station: a) S, Love \& Rayleigh waves; b) ScS wave
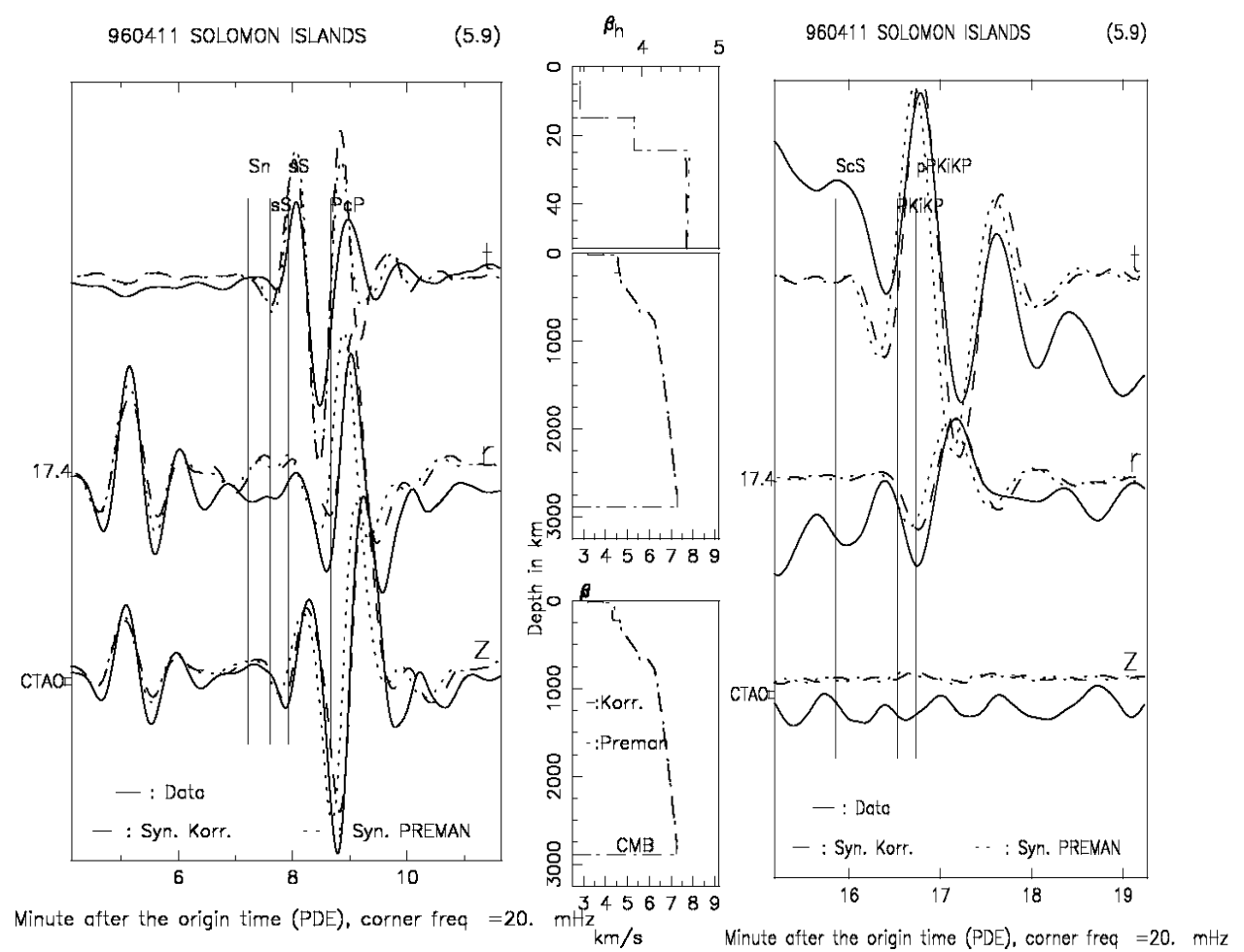

Fig. 4. The seismogram fitting and analysis of the B041196C earthquake in CTAO station: a) S, Love \& Rayleigh waves; b) ScS wave

This indicates that the $\mathrm{S}$ wave velocity anomaly under the OJP area to the southeast direction has a positive value, especially large value on $b_{h}$ velocity. The area of the wave paths between hypocenter and the station crosses the compressed ocean crust of the South West Pacific, so it gives the positive $\mathrm{S}$ wave velocity anomaly. The positive speed anomaly is not only occurred in upper mantle layers or the $300 \mathrm{~km}$ uppers earth layers, as stated in the paper of Gomer and Okal [1] or Richardson et al. [3], but also in all earth mantle layers. The fitting of the synthetic $\mathrm{ScS}_{2}$ wave to the measured one is illustrated in the Fig. $2 b$.

The Fig. 3a shows the seismogram compare at the HNR station whose epicentral distance is $2.2^{0}$ from the hypocenter. With epicentral distance as small as this, the seismogram is classed as strong motion, but we can see that the GEMINI program can still produce this strong motion seismogram. However, the amplitude of the synthetic wave is bigger than the measured seismogram. This mistake is the error on the CMT solution tensor of the earthquake [10] that describes the direction of the fault plane and the released energy by the earthquake. 
The released energy stated in the CMT solution is bigger than the necessary. Nevertheless, the fitting is tried only on the location of the amplitude maximum. The Results show that the speed anomaly is negative compared with the positive anomaly to the wave path to MSVF. This small negative anomaly is also shown in the Fig. 3b, that the anomaly continue in earth layers below the upper mantle as far as CMB (Core Mantle Boundary), to fit the $\mathrm{ScS}$ wave.

The Fig. 4 presents the seismogram comparison between the measured and the synthetic seismograms at CTAO observatory station. It can be seen that the PREMAN earth model provides synthetic seismogram that arrives a little earlier than the measured seismogram, perceived on the $\mathrm{P}$ and $\mathrm{S}$ waves, and the Love and Rayleigh surface waves to the $\mathrm{ScS}$ wave. This shows that the anomaly especially in the upper mantle layers to the north-west of OJP has really the negative values, as stated by Richardson et al. [3]. However, the negative correction must be also imposed in mantle layers until $\mathrm{CMB}$, not only in $300 \mathrm{~km}$ the uppers earth mantle layers.

The Fig. 5 shows the seismogram comparison at the WRAB station. We see that the epicentral distance is quite great, so that the S, SS and Love waves are well separated, but the synthetic seismogram from PREMAN arrives a little later than the measured wave phase. This delay is also observed in the wave comparison of $\mathrm{ScS}_{2}$ wave. This shows that the earth mantle model beneath OJP in the direction to South West has the positive anomaly down to the $\mathrm{CMB}$, compared to the $\mathrm{S}$ wave velocity structure in the PREMAN earth model.

Fig. 6 presents the seismogram comparison at the NWAO station. The epicentral distance of this station is big enough, so that we can see that the waveforms of S, SS and Love waves are well separated. We can observe that the synthetic seismogram from the PREMAN provides synthetic waves that arrive later than measured wave phases. The biggest delay is occurred to the Rayleigh wave, while smaller later arrival time can also be observed on the SS and S body waves. This indicated that the biggest positive speed anomaly is imposed in upper mantle layers, but smaller factors are also continued down to earth mantle layers until the CMB depth.

The seismogram comparison of the B041196C earthquake in the TAU observatory station is presented in the Fig. 7. We can see that the synthetic seismogram from the PREMAN provides later arrival time than the measured wave phase. This indicated that the positive anomaly from the upper mantle layers down to CMB, as being pointed out by the fitting of the $\mathrm{ScS} 2$ wave, in Fig. 7b. To achieve the third amplitude height in the Love waveform which is similar to the amplitude pattern of the measured Love wave, the thickness of the earth's crust is changed became thinner than in the PREMAN earth model, that is $18 \mathrm{~km}$. However the height of the Love wave can not be reached, where the mistake stems from the direction of the fault plane in the CMT solution.

The Fig. 8 presents the seismogram comparison in the GUMO observatory station. Wave path from earthquake hypocenter to the observatory station should pass the Ocean earth's crust model, but the thickness of the earth's crust provides the significant influence in the form of the Love wave [9]. This indicates that the model of the standard earth's crust can be used to replace the Ocean earth crust model. This indicates that the similar thickness could be observed to old Ocean earth crust [11]. Further perceiving, the positive anomaly continues through deeper earth mantle layers, to get better fitting to the $\mathrm{S}$ body wave.

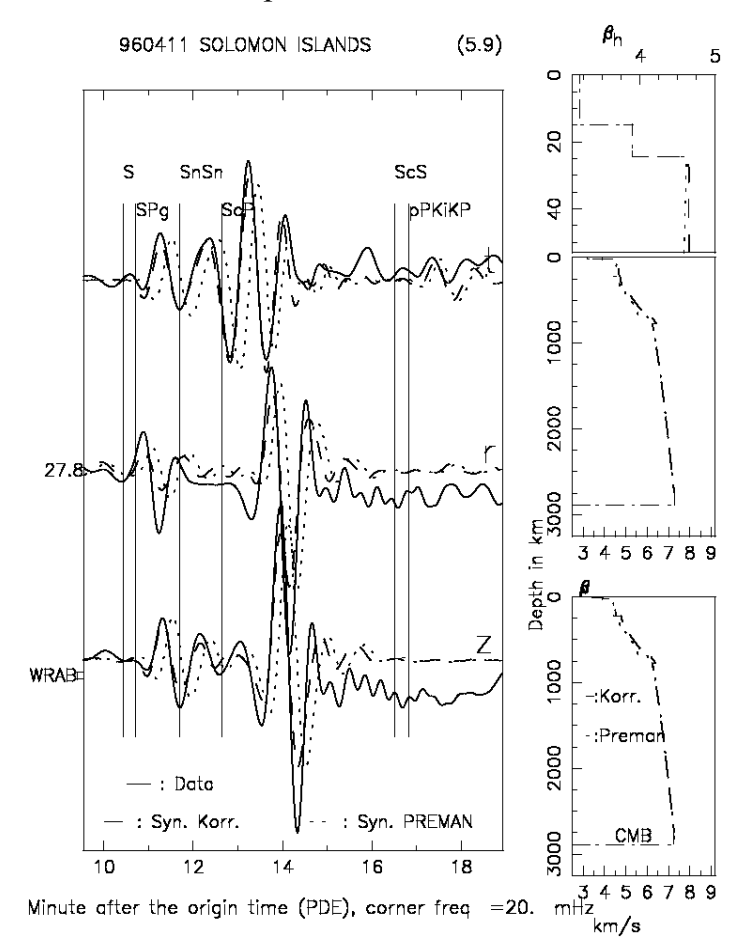

960411 SOLOMON ISLANDS

(5.9)

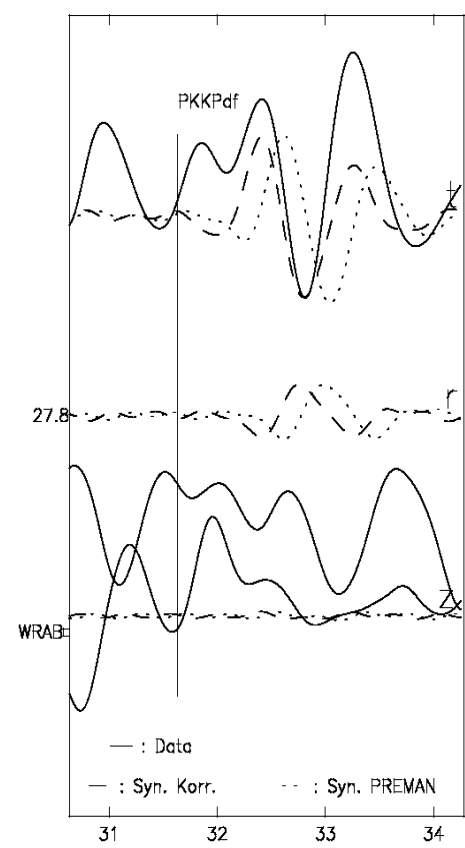

Fig. 5. The seismogram fitting and analysis of the B041196C earthquake in WRAB station: a) S, Love \& Rayleigh waves; b) $\mathrm{ScS}_{2}$ wave 


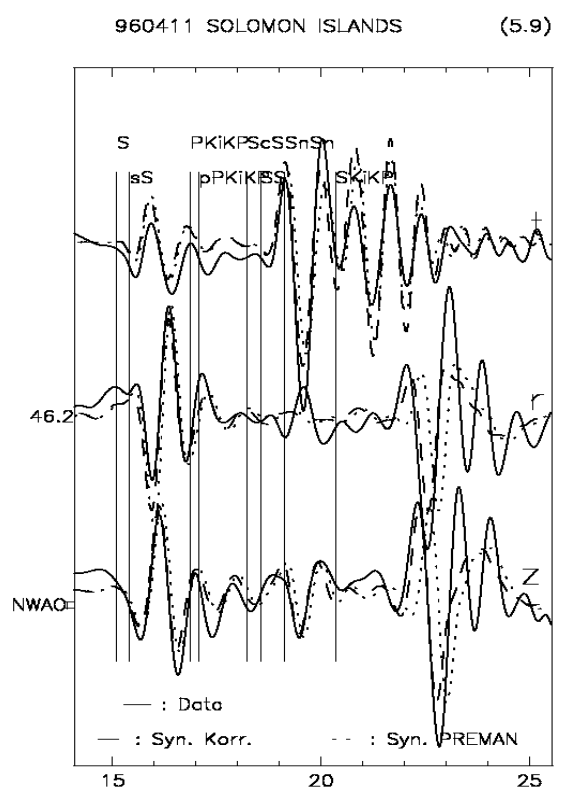

Minute after the origin time (PDE), corner freq $=20$
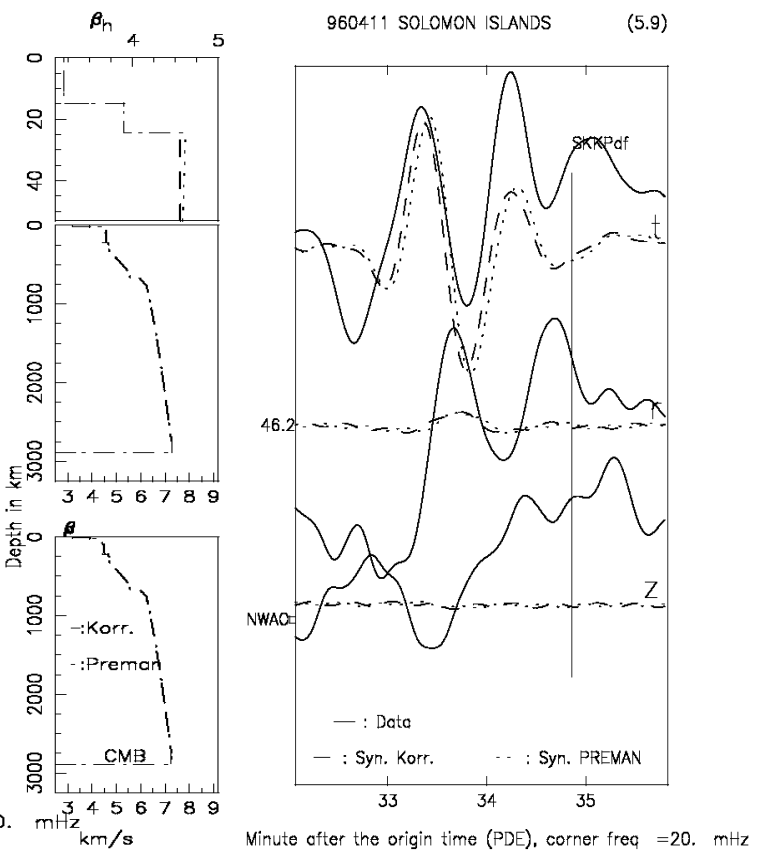

Fig. 6. The seismogram fitting and analysis of the B041196C earthquake in NWAO station: a) S, Love \& Rayleigh waves; b) $\mathrm{ScS}_{2}$ wave

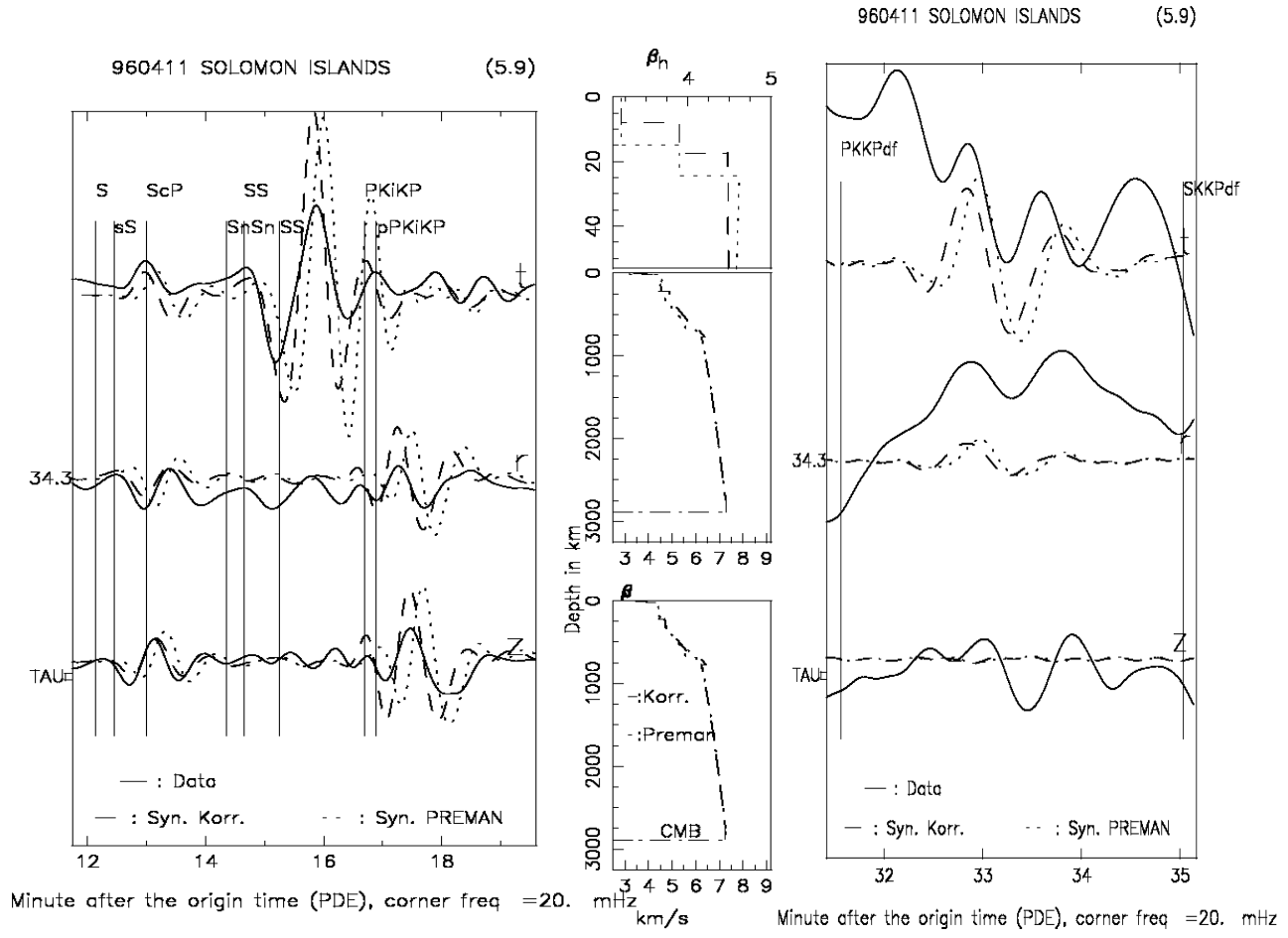

Fig. 7. The seismogram fitting and analysis of the B041196C earthquake in TAU station: a) S, Love \& Rayleigh waves; b) ScS 2 wave

The seismogram comparison in the PMG observatory station is shown in the Fig. 9. The wave path from hypocenter to the PMG station passes the medium of OJP. We can see that upper mantle layers have the negative anomaly, see the upper right box. This negative anomaly continues in layers beneath the upper mantle, as being required to get the fitting to the $\mathrm{sP}$ wave.

\section{DISCUSSION}

After the research results are obtained, furthermore is discussed with the research results of two previously papers (paper 1 and paper 2), where the seismology research is carried out in the same area. The discussions are only stressed to 3 stations that are HNR, MSVF and CTAO. Paper 2 wrote that the thickness of the earth's crust under OJP $33 \mathrm{~km}$, and to the south direction is 38 $\mathrm{km}$.

After the seismogram comparison in the HNR station and MSVF, the thickness of the earth's crust stays $25 \mathrm{~km}$, as stated in PREMAN earth model. The Love waveform is sensitive to the thickness of the earth's crust [9] and this has not been yet exploited by the other seismologist, in which their interpretation of earth model still based on 
the arrival time or dispersion analysis.

They mentioned that the $\mathrm{S}$ wave velocity anomaly of the negative under $5 \%$ to the upper mantle layers, whereas this research shows that this anomaly is only obtained to the HNR station and PMG. This negative

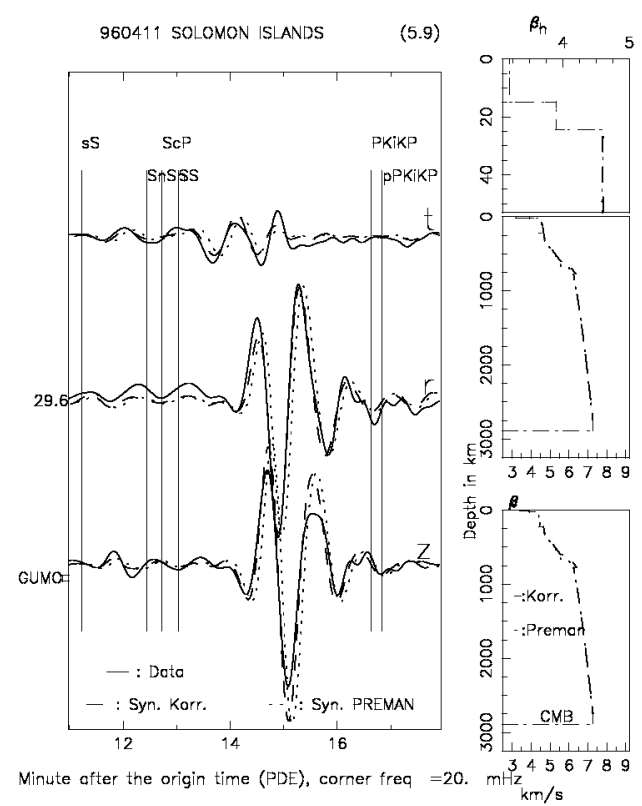

Fig. 8. The seismogram fitting and analysis of the B041196C earthquake in GUMO station
Anomaly is only encounter in the east direction of OJP. However the anomaly is not only occurred in uppers 300 $\mathrm{km}$ the earth mantle layers, but continues down to earth mantle layers beneath the OJP.

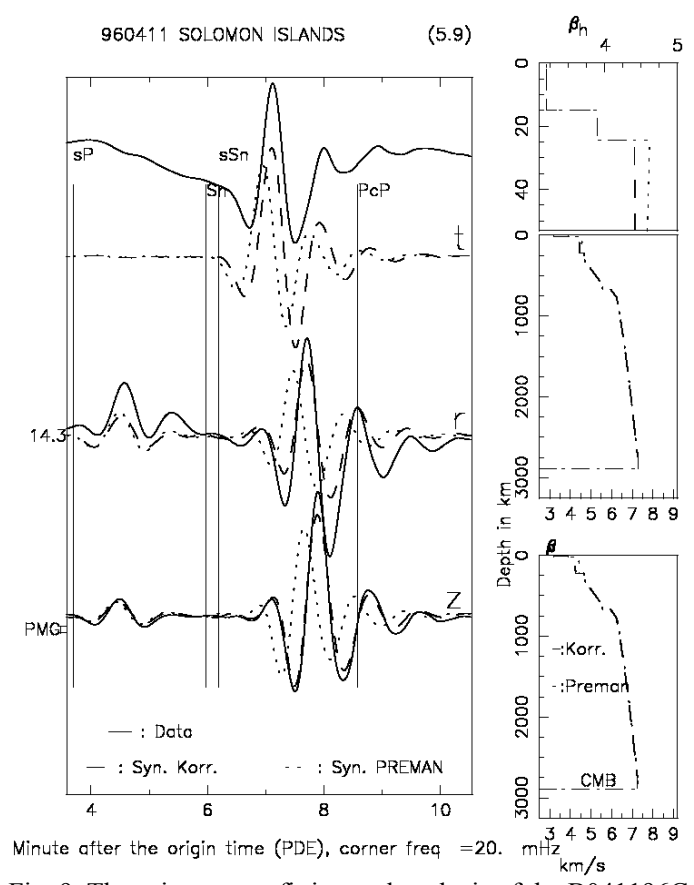

Fig. 9. The seismogram fitting and analysis of the B041196C earthquake in PMG station

TABLE 2

The Velocity Structure of S Wave Between The Preman Earth Model and The Corrected Model of The Earth for The

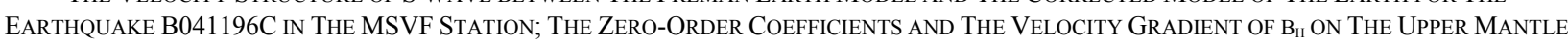
(6151 6346.6 KM) ARE ALSO SHOWN

\begin{tabular}{|c|c|c|c|c|c|c|c|}
\hline \multicolumn{4}{|c|}{ PREMAN } & \multicolumn{4}{|c|}{ Corrected } \\
\hline Radius & $\beta_{\mathrm{v}}$ & $\beta_{\mathrm{h}}$ & $\eta$ & Radius & $\beta_{\mathrm{v}}$ & $\beta_{\mathrm{h}}$ & $\eta$ \\
\hline 3480 & 6.9254 & 6.9254 & 1.00 & 3480 & 6.9604 & 6.9254 & 1.0048 \\
\hline 3630 & 11.1671 & 11.1671 & 1.00 & 3630 & 11.2121 & 11.1671 & 1.0062 \\
\hline 5600 & 22.3459 & 22.3459 & 1.00 & 5600 & 22.4959 & 22.3859 & 1.0159 \\
\hline 5701 & 9.9839 & 9.9839 & 1.00 & 5701 & 10.1639 & 10.1389 & 1.0044 \\
\hline 5771 & 22.3512 & 22.3512 & 1.00 & 5771 & 22.5312 & 22.5062 & 1.0044 \\
\hline 5971 & 8.9496 & 8.9496 & 1.00 & 5971 & 9.1296 & 9.1456 & 0.9968 \\
\hline \multirow[t]{2}{*}{6151} & 5.8582 & -1.0839 & 3.36 & 6151 & 5.9602 & 6.5592 & 0.8769 \\
\hline & -1.4678 & 5.7176 & -2.47 & & -1.4676 & -1.4278 & \\
\hline \multirow[t]{2}{*}{6291} & 5.8582 & -1.0839 & 3.36 & 6291 & 5.9602 & 6.5592 & 0.8769 \\
\hline & -1.4678 & 5.7176 & -2.47 & & -1.4676 & -1.4278 & \\
\hline 6346.6 & 3.9000 & 3.9000 & 1.00 & 6346.6 & 3.9000 & 3.9000 & 1.0000 \\
\hline 6356 & 3.2000 & 3.2000 & 1.00 & 6356 & 3.2000 & 3.2000 & 1.0000 \\
\hline
\end{tabular}


Table 2 presents an example of the $\mathrm{S}$ wave velocity in various earth mantle layers, in which the PREMAN earth model was compared with the corrected model of the earth between the earthquake hypocenter B041196C and the MSVF observatory station. The $\mathrm{S}$ wave velocity structure of the other earthquake can be seen by noticing the small box that contains the velocity structure of the $\mathrm{S}$ wave that lies on the right side of Fig. 3 through Fig. 9. We can see that the vertical anisotropy ( $\eta$ values) occurs in all of the mantle layers, not only in the upper mantle layers as stated in the PREMAN earth model. We notice further by comparing the second and third columns with each of the fifth and the sixth column that generally there is positive anomaly in the $\mathrm{S}$ wave velocity structure of all layers of the mantle.

The anomaly on $\mathrm{S}$ wave velocity occurs on all mantle layers. To find a matching on the $\mathrm{S}$ wave ( $\mathrm{SV}$ and $\mathrm{SH}$ ) on the seismogram of some earthquakes, we need correction with a weaker magnitude at the mantle layers until CMB depth, and its values are different for both kinds of $\beta$. It indicates that the vertical anisotropy feature also occurs on the mantle layers below the upper mantle. The anisotropy features are not used in the seismology research that based on the travel time data, because we find difficulties to observe the travel time difference of the $\mathrm{S}$ wave on the three Cartesian-components. This result is different from that of Gomer and Okal [1] and Richardson et al. [3] whose investigation result is based on a dispersion analysis of the Rayleigh wave or travel time difference of $\mathrm{ScS}_{\mathrm{n}}-\mathrm{ScS}_{\mathrm{j}}$ waves. The Figure contain the phases of the repetitive core reflected $\mathrm{ScS}$ and $\mathrm{ScS}_{2}$ waves, where the obtained matching is by changing $\beta_{\mathrm{v}}$ in the base mantle layers, while the change in $\beta_{\mathrm{h}}$ does not bring a significant improvement on the matching of the core reflected wave. While according to $\mathrm{Yu}$ Guo et al. [12], to obtain a matching on the wave $\mathrm{ScSH}$, the structure of $\beta_{\mathrm{h}}$ velocity in the layers near CMB has strong influence.

Gomer and Okal [1] wrote, that the arrival time difference between $\mathrm{ScS}_{2}$ and $\mathrm{ScS}$ wave phases in the CTAO station of 6 seconds, that means for one path of $\mathrm{ScS}$ needs 3 seconds. They interpreted this negative difference because of inhomogeneity in upper mantle layers. Contrary, this research measured the time discrepancy for the wave $\mathrm{ScS}$ is 4 seconds, whereas the $\mathrm{ScS}_{2}$ of 7 seconds. To achieve the fitting to the seismogram in the CTAO station, the negative correction is imposed in upper mantle layers for the Rayleigh wave, and the negative correction in earth mantle layers beneath it down to the $\mathrm{CMB}$, to get the fitting for $\mathrm{ScS}$ wave.

The negative anomaly in the direction to the east and positive anomaly to the other side is not linked with the thermodynamics activity, because there is no volcanic activity along the wave-propagating medium. This anomaly is caused only by the change in the chemistry characteristics in the rocks constituted earth mantle layers beneath the OJP.

\section{CONCLUSION}

This research investigates the $\mathrm{S}$ velocity structure beneath OJP through the seismogram comparison in the time domain and the three components simultaneously, where the used earth model has property of vertical anisotropic. The travel time difference is measured through the waveform comparison.

The negative travel time differences is only encountered at two stations, that is HNR and PMG, while the other stations show that the synthetic wave phase from the PREMAN provides later arrival time compared to the measured wave phase. Research results with waveform in three components show different results from the other seismological research in same the OJP region. Some forms of radial anisotropy are disallowed by other seismic datasets, for example SKS splitting, differential $\mathrm{PcP}$ and $\mathrm{P}$ travel times, and $\mathrm{P}$ tomography.

Heterogeneity is also encountered in the earth mantle layers that deeper than $300 \mathrm{~km}$ to get the fitting to waveform and arrival time of the core reflected wave.

\section{REFERENCES}

[1] Gomer, B.M. and Okal, E.A., 2003, Multiple-ScS Probing of the Ontong-Java Plateau, Phys. of the Earth and Plan. Int., 138, 317 -331 .

[2] Dziewonski, A.M. and Anderson, D.L., 1981, Preliminary Reference Earth Model, Phys. of the Earth and Plan. Int., 25, $297-356$

[3] Richardson, W.P., Okal, E.A., and Van der Lee, S., 2000 Rayleigh- Wave Tomography of the Ontong-Java Plateau, Phys. Earth Plan. Int., 118, 29 - 51.

[4] Evans, J.R. and Sacks, I.S., 1979, Deep Structure of the Iceland Plateau. J. Geophys. Res., 84, 6859- 6866.

[5] Okal, E.A. and Anderson, D.L., 1975, A study of Lateral Inhomogeneities in the Upper Mantle by Multiple ScS TravelTime Residuals. Geophys. Res. Lett., 2, 313 - 316.

[6] Sipkin, S.A. and Jordan, T.H., 1976, Lateral Heterogeneity of the Upper Mantle Determined from the Travel Times of Multiple ScS. J. Geophys. Res., 81, $6307-6320$.

[7] Dalkolmo, J., 1993, Synthetische Seismogramme Fuer Eine Sphaerisch Symmetrische, Nichtrotierend Erde Durch Direkte Berechnung der Greenschen Funktion, Diplomarbeit, Inst. fuer Geophys., Uni. Stuttgart.

[8] Friederich, W. and Dalkolmo, J., 1995, Complete Synthetic Seismograms for a Spherically Symmetric Earth by a Numerical Computation of the Green's Function in the Frequency Domain, Geophys. J. Int., 122, $537-550$.

[9] Santosa, B.J., 1999, Moeglichkeiten and Grenzen der Modellierung Vollstaendiger Langperiodischer Seismogramme, Doktorarbeit, Berichte Nr. 12, Inst. fuer Geophysik, Uni. Stuttgart.

[10] Dreger, D.S., 2002, Time-Domain Moment Tensor INVerse Code (TDMT_INVC), The Berkeley Seismological Laboratory (BSL), report number 8511 .

[11] Talandier, J. and Okal, E.A., 1998, On the Mechanism of Conversion of Seismic Waves to and from $\mathrm{T}$ Waves in the Vicinity of Island Shores. Bull. Seismol. Soc. Am., 88, $621-$ 632

[12] Yu Guo, J., Lerner-Lam, A. L., Dziewonski, A.M. and Ekström, G., 2005, Deep Structure and Seismic Anisotropy Beneath the East Pacific Rise, Earth and Planetary Science Letters, 232, 259 272 